Published in final edited form as:

Transl Res. 2017 May ; 183: 14-25. doi:10.1016/j.trsl.2016.12.004.

\title{
The Metabolic Syndrome and Chronic Kidney Disease
}

\author{
Xin Zhang and Lilach O. Lerman \\ Division of Nephrology and Hypertension, Mayo Clinic, Rochester, MN, United States
}

\begin{abstract}
The metabolic syndrome (MetS) is a cluster of cardiovascular risk factors including insulin resistance (IR), dyslipidemia and hypertension, which may also foster development of chronic kidney disease. The mechanisms of MetS-induced kidney disease are not fully understood. The purpose of this review is to summarize recent discoveries regarding the impact of MetS on the kidney, particularly on the renal microvasculature and cellular mitochondria. Fundamental manifestations of MetS include insulin resistance (IR) and adipose tissue expansion, the latter promoting chronic inflammation and oxidative stress that exacerbate IR. Those in turn can elicit various kidney injurious events through endothelial dysfunction, activation of the reninangiotensin-aldosterone system, and adipokine imbalance. IR and inflammation are also major contributors to microvascular remodeling and podocyte injury. Hence, these events may result in hypertension, albuminuria, and parenchymal damage. In addition, dyslipidemia and excessive nutrient availability may impair mitochondrial function and thereby promote progression of kidney cell damage. Elucidation of the link between MetS and kidney injury may help develop preventative measures and possibly novel therapeutic targets to alleviate and avert development of renal manifestations.
\end{abstract}

\section{Keywords}

metabolic syndrome; insulin resistance; kidney; microcirculation

\section{Epidemiology}

According to the American Heart Association, individuals with the metabolic syndrome (MetS) show 3 or more of the following conditions: 1) Central or abdominal obesity (by waist circumference); 2) Elevated triglyceride levels; 3) Low high-density lipoproteins (HDL); 4) Hypertension; 5) Elevated fasting glucose.[1] The International Diabetes

Correspondence: Lilach O. Lerman, MD, PhD, Division of Nephrology and Hypertension, Mayo Clinic, 200 First Street SW, Rochester, MN 55905., Phone: (507)-266-9376; Fax: (507)-266-9316, lerman.lilach@ mayo.edu.

Publisher's Disclaimer: This is a PDF file of an unedited manuscript that has been accepted for publication. As a service to our customers we are providing this early version of the manuscript. The manuscript will undergo copyediting, typesetting, and review of the resulting proof before it is published in its final citable form. Please note that during the production process errors may be discovered which could affect the content, and all legal disclaimers that apply to the journal pertain.

Disclosure

None.

All authors have read the journal's policy on disclosure of potential conflicts of interest.

All authors have read the journal's authorship agreement and that the manuscript has been reviewed by and approved by all named authors. 
Federation criteria are similar, but more specific regarding the definition of central obesity categorized by country or ethnic group.[2] A waist circumference greater than $94 \mathrm{~cm}$ for Europids males is considered central obesity, whereas $90 \mathrm{~cm}$ are indicative in Asian males.

Although greater awareness of MetS may have contributed to improvements in treatment of risk factors like hypertension and diabetes, nearly $35 \%$ of all adults and $50 \%$ of those 60 years or older were still estimated to have MetS.[3] MetS is an important contributor to cardiovascular morbidity and mortality. Among 12,561 subjects from the United States Third National Health and Nutrition Examination Survey, 13.3\% of the excess cardiovascular mortality in the United States could be attributed to higher prevalence of MetS and MetS with baseline cardiovascular disease.[4] Moreover, Mets often progresses to frank type-2 diabetes, particularly in subjects with hyperglycemia. In a recent study of 28,209 patients, yearly conversion rates to diabetes were only $0.6 \%$ in MetS individuals with normoglycemia or mild hyperglycemia, but $2.5 \%$ in those with intermediate hyperglycemia (6.1-7.0 mmol/L)[5], leading to particularly elevated risk for cardiovascular complications.

Studies have suggested that individuals with MetS are also at increased risk for developing chronic kidney disease (CKD), reflected by microalbuminuria[6, 7] and renal dysfunction. [8] Patients with 1-2 traits of MetS are twice more likely to have microalbuminuria than those without the syndrome, and the likelihood rises to $130 \%$ in those with more than 3 traits.[6] In a study including 5,800 patients with type-2 diabetes, MetS independently predicted the new-onset of CKD.[4] After adjustments for diabetes and hypertension, MetS remained an independent risk factor contributing to development of CKD, defined as a fall the kidney function over a 9-year follow-up.[8] Patients with MetS undergoing nephrectomy also showed a higher prevalence of features characterizing CKD, including global and segmental glomerulosclerosis and loss of renal function, compared to those without MetS. [9] Recent studies also suggest that the presence of MetS before renal transplantation predicts subsequent development of new-onset diabetes after transplantation, and the presence of MetS after transplantation adversely influenced allograft survival.[10,11] Over an 18-month follow-up post-transplantation, the hazard ratio for creatinine elevation was 2.6, and patient survival was significantly diminished.[10] These observations establish MetS as a trigger for renal injury in CKD, which magnifies the adverse impact of other insults. Given the central role of the kidney in maintenance of bone homeostasis,[12] MetS may also contribute to bone mineral disorders in these subjects.[13]

The pathways activated by MetS to induce kidney disease are not fully understood. Over the past few years, studies have identified several new injurious pathways that MetS activates in the kidney.[14] Central tenets of MetS include insulin resistance (IR) and chronic inflammation, a major contributor to microvascular remodeling. In addition, dyslipidemia and excessive nutrient availability may induce mitochondrial dysfunction; adipokines, the renin-angiotensin system, and oxidative stress may permit development of hypertension. Better understanding of the mechanisms by which MetS injures the kidney may direct future studies and possibly novel therapeutic targets to alleviate and prevent the development of renal manifestations of MetS. 


\section{Microvascular Remodeling}

We and others have observed that in humans and animals MetS induced renal parenchymal damages, such as tubular atrophy and interstitial fibrosis.[9, 15] Microvascular remodeling manifesting as arterial and arteriolar sclerosis within kidney lesions in patients with MetS have also been observed,[9] and ultrasound revealed elevated resistive indices in intra-renal inter-lobar arteries, $[16,17]$ indicating vasoconstriction and microvascular remodeling. Direct evidence for the effects of MetS on microvessels has been obtained from studies in animal models. In rats, a 6-week MetS diet (60\% fructose) induced wall thickening in outer cortical and juxtamedullary afferent arterioles,[18] mimicking arteriolar sclerosis observed in humans. In MetS Ossabaw pigs, dysregulated angiogenesis was observed after a sixteenweek diet, accompanied by increased tissue fibrosis,[15] partly due to elevation of Angiotensin II (AngII), consistent with activation of the renin-angiotensin-aldosterone system observed in MetS.[19] Accumulation of visceral adipose and fat infiltration of the kidney may also induce inflammation-driven neovascularization through multiple cytokines that are enriched in adipose tissue, such as tumor necrosis factor (TNF)- $a$ and interleukin-6. $[20,21]$

Using a 3-dimensional micro-CT, we found that at its early stage MetS in fact stimulated microvascular proliferation in the kidney.[22, 23] The increase in microvascular density (Figure 1, Top) was associated with upregulated expression of vascular endothelial growth factor (VEGF),[22] possibly secondary to oxidative stress[24] commonly seen in MetS, and hyperinsulinemia that directly increases VEGF production.[25] The small microvessels (20$40 \mu \mathrm{m})$ that proliferated $[22,23]$ may contribute to maintain renal perfusion, and may initially account for elevated renal blood flow (RBF) and glomerular filtration rate (GFR) that characterize the early stage of MetS. However, those newly generated vessels often have disorganized architecture, because following a 16-week MetS diet they become more torturous,[23] suggesting that at later stage of MetS intra-renal vessels may be dysfunctional and unstable. In addition, sustained mechanical strain on glomerular capillaries due to hyperfiltration likely increases propensity for microvascular loss.[26]

Furthermore, under physiological condition insulin may regulate GFR through local renal vasodilation, which can be blocked by indomethacin[27] and augmented by activation of endothelial nitric oxide (NO) synthase.[28] However, this effect of insulin might be lost over time in MetS subjects with IR,[29] who manifest endothelial dysfunction due to downregulated expression of eNOS and increased endothelin-1 levels.[30] Uric acid, which is often elevated in MetS, also inhibits NO production, thus contributing to endothelial dysfunction.[18] Renal microvascular endothelial dysfunction increases glomerular capillary wall permeability and albuminuria, which may also promote glomerular capillary loss[21] in prolonged MetS and progression of renal injury. Indeed, MetS patients show a steeper decrease in kidney function over time compared to non-MetS patients, suggesting limited renal reserve, which might be the consequence of kidney vascular remodeling and parenchymal damage in MetS.[9] Moreover, MetS may impose vascular remodeling and accelerate development of atherosclerotic lesions. Renal artery stenosis, detected in $16 \%$ patients with cardiovascular events,[31] further decreases blood supply to the kidney and exacerbates renal damage. Indeed, in post-stenotic swine kidneys, MetS precipitates or 
magnifies loss of microvessels,[15] thereby aggravating tissue injury. This synergistic interaction between MetS and renal ischemia is associated with increased oxidative stress and inflammation, which disrupt microvascular stability.[15, 23] As renal artery stenosis is increasingly observed in the aging modern society, the link between MetS and the severity of intra-renal microvascular remodeling in stenotic kidneys needs to be considered during management of these patients.

\section{Inflammation and insulin resistance}

Low-grade chronic inflammation is a hallmark of MetS[32], and its the severity seems to depend on the prevalent number of components of MetS.[33] In fact, the pivotal role of metabolically-induced inflammation is underscored by the proposed term "metaflammation".[34]

Animal studies have highlighted the kidney as a target organ often involved in the inflammatory response.[15, 35] A 16-week MetS diet in pigs elevated the levels of circulating oxidized low-density lipoprotein (LDL) and soluble (s)E-selectin that recruits inflammatory cells,[15] and increased infiltration of pro-inflammatory macrophages in the kidney (Figure 1, Bottom), accompanied by development of glomerulosclerosis.[15] Similary, Zucker fatty diabetic rats show macrophage infiltration in the tubular-interstitium space and neutrophils in peritubular capillaries, associated with wide-spread fibrosis.[35] Hence, inflammation may mediate development of renal fibrosis and glomerulosclerosis in MetS.

One of the plausible hypotheses is that MetS-induced disruption in many physiological regulatory systems due to excessive energy intake, provoking stressor stimuli that subsequently trigger inflammatory and oxidative pathways.[34] This response might aim to block major anabolic signaling pathways, such as the insulin/insulin growth factor (IGF) pathway, thereby diverting energy sources from synthetic pathways.[34] In vitro studies demonstrated that the inflammatory mediator interleukin (IL)-6 exerts inhibitory effects on IGF-1 signaling pathways (extracellular-regulated protein kinase (ERK)1/2 and Akt) by blocking its receptor substrate (IRS)-1[36], or by increasing its clearance.[37]

Adipose tissue expansion, a central tenet of MetS, represents a major source of inflammatory cytokines. In human subjects adipocyte size correlates with levels of TNF-a, IL-6, and high-sensitivity C-reactive protein (CRP).[38] Experimental studies in MetS animals have shown substantial infiltration of inflammatory macrophages and TNF- $a$ in the abdominal and peri-renal fat tissue[15, 39], which could serve as a channel for inflammatory cytokines to access the kidney. In addition, renal arterial endothelial function was blunted when incubated in vitro with perirenal fat harvested from MetS pigs, and restored by TNF-a inhibitor, substantiating its injurious effect on the renal vasculature.[39] Weight loss improves both inflammatory (CRP, TNF-a, IL-6 and leptin) and anti-inflammatory (adiponectin) markers in human subjects[40, 41], and MetS rats treated with antiinflammatory mycophenolate mofetil showed reduced systemic and renal inflammation and limited renal fibrosis.[35] Therefore, measures to control inflammation in MetS may be beneficial for the kidney. 
Even in the absence of other co-existing MetS components, inflammatory mediators alone can trigger IR. For example, in humans uremia can cause IR by disrupting insulin signaling. [42] In vitro, stimulated macrophages produce IL- $1 \beta$ and IL-18, contributing to pancreatic $\beta$-cell death with chronic hyperglycemia and progression of diabetes.[43] These observations suggest that inflammation can be upstream to metabolic derangement. Clinical studies have found that Salsalate, a prodrug of salicylate which suppresses inflammation, attenuates IKK $\beta / N F-\kappa B$ activity, improves glycemic control in patients with type- 2 diabetes, [44] and alleviates IR.[45] TNF-a blockade improved fasting glucose and improved the levels of anti-inflammatory adiponectin in obese subjects with abnormal glucose homeostasis.[46] Clearly, the cause and effect relationship between inflammation and MetS remains to be discerned, and the ability of management of inflammation to alleviate kidney injury in MetS warrants further studies.

Evidence indicated that IR is not infrequently associated with CKD.[47, 48] In a 9-year study, the severity of IR was directly related to the risk of developing CKD.[48] In slightly overweight non-diabetic patients, the prevalence of CKD significantly and progressively rises with increasing levels of serum insulin and IR.[49] As mentioned earlier, hyperinsulinemia may induce glomerular hyperfiltration, endothelial dysfunction, and increased vascular permeability,[50] leading to albuminuria. In nondiabetic subjects, even a short-term insulin infusion increases urinary albumin excretion.[51] In turn, albumin in the tubular lumen may lead to tubulo-interstitial injury and fibrosis.[52] The link between IR and kidney disease might be attributable to the dependence of the kidney on insulin, which binds to all nephron cells, including the glomerulus and the entire length of the renal tubules. $[53,54]$ Particularly, the glomerular podocytes, major components of the glomerular filtration barrier, have higher expression of insulin receptors compared with endothelial and mesangial cells,[55] and insulin may control podocyte contractility associated with glomerular permeability.[56, 57] Conceivably, changes in the abundance or sensitivity of insulin receptors in MetS may regulate renal physiology and/or pathology. Furthermore, elevated insulin levels have been found to stimulate IGF-1 production, which increases connective tissue growth factor, causing renal fibrosis.[58] Indeed, insulin-sensitizing compounds, such as thiazolidinediones (TZD), abrogate interstitial fibrosis in Zucker obese rats fed a high-protein diet.[59] These findings suggest that the interaction of insulin with its receptor bears direct ramification for renal structural and functional impairment in MetS. As hyperglycemia becomes more evident, advanced glycation end products (AGEs) also participate in kidney damage via their receptors on podocytes and endothelial cells. Deposition and activation of AGEs promote cellular hypertrophy and apoptosis, as well as inflammation.[60] Whether systemic levels of AGEs correlate with severity or progression of kidney damage in MetS needs to be examined.

More recently, adipocytokines linked to IR, low grade inflammation, endothelial dysfunction, and vascular damage have been proposed to modulate kidney function.[61] Adiponectin, which is linked to insulin sensitivity, regulates function of podocytes, major sites of adiponectin receptor in the kidney.[62] Mice with reduced or abolished expression of adiponectin exhibit exacerbation of podocyte injury, albuminuria, and renal fibrosis compared with wild-type animals.[63-65] The regulatory role of adiponectin on podocyte function is likely mediated through the 5' AMP-activated protein kinase (AMPK) pathway, 
and adiponectin-knockout mice exhibit increased albuminuria and fusion of podocyte foot processes. In cultured podocytes, adiponectin administration was associated with increased activity of AMPK, and both adiponectin and AMPK activation reduced podocyte permeability to albumin and podocyte dysfunction.[64]

Conversely, serum levels of leptin, which regulates hunger and satiety, are 5-10-fold higher in obese than in healthy individuals. In vitro, leptin induces glomerular mesangial cell hypertrophy,[66] which subsequently increases the amount of filtered protein and albumin. Leptin has been shown to activate several cell signaling pathways in a cell-specific manner. In vitro, leptin can alter rat glomerular cell size via activation of the mitogen-activated protein kinase pathway through ERK 1/2,[67] and hypertrophy in glomerular mesangial cells via activation of phosphoinositide 3-kinase and ERK1/2.[66] Leptin enhanced tissue growth factor (TGF)- $\beta$ /smad signaling in rat kidney fibroblasts, and leptin deficient ob/ob mice had significant reduction in TGF- $\beta$ mRNA levels, Smad-2/3 activation, and fibrotic tissue.[68]

Resistin, an adipose sensor that contributes to obesity,[69] is also independently associated with albumin excretion.[70] Although the mechanisms of resistin-related kidney injury is less clear, studies have shown that it upregulates expression of Intercellular Adhesion Molecule-1 and vascular cell adhesion molecule-1.[71] In addition, both leptin and resistin enhance renal sympathetic nerve activity,[72] the latter possibly via phosphatidylinositol 3kinase.[73]

Therefore, IR and dysregulated adipokines in concert target different renal cell types via various pathways to elicit kidney disease in MetS. Nonetheless, while IR is speculated as an important mediator of MetS-related CKD,[19] its complex role in regulating renal function, solute transfer, and blood pressure needs to be better defined.

\section{Obesity}

Substantial evidence has shown that obesity directly influences renal hemodynamics and structure. A 1-month high-fat diet promptly increases the extracellular fluid and causes a shift in sodium balance.[74] Elevated aldosterone levels due to activation of the reninangiotensin-aldosterone system and increased sympathetic activity in obesity are likely the major culprits that promote sodium retention[75, 76] by increasing tubular reabsorption. Elevated salt reabsorption at the segment proximal to the macular densa also induces a rise in GFR through tubulo-glomerular feedback, contributing to hyperfiltration.

Yet, obesity-related glomerulopathy (ORG) may not be mediated solely by hemodynamic factors. As an individual gains weight, each podocyte must undergo mechanical stretch to cover a larger surface area to accommodate the increased glomerular volume,[77] resulting in decreased podocyte density and increased foot process width in adults with ORG.[78] Podocyte number increases in size in animals fed ad libitum in proportion to the extent of glomerular hypertrophy at the early stage.[79] Over time, when podocyte enlargement is no longer proportional to glomerular hypertrophy, podocytes fail and detach, causing localized denudation of the glomerular basement membrane, subsequent adhesions to the Bowman capsule and parietal cell coverage, forming a nidus for development of segmental sclerosis, 
[80] and result in proteinuria.[81] In addition, an average of 12\% individuals with ORG progress to focal segmental glomerulosclerosis (FSGS), which typically affects hypertrophied glomeruli.[82, 83] Although those pathological alterations can be prevented by calorie restriction,[79] development to FSGS is often irreversible and may eventually lead to end-stage renal disease.[81]

\section{Oxidative stress and mitochondrial dysfunction}

Oxidative stress, characterized by elevated reactive oxygen species (ROS) levels, causes damage to proteins, lipids and DNA, and has been proven to play an important role in MetS. $[84,85]$ In humans, lipid peroxidation, represented by plasma thiobarbituric acid reactive substance and urinary 8-epi-prostaglandin-F2a, correlate with BMI and waist circumference.[86]

A major source of ROS MetS is the NADPH oxidase (NOX) family of enzymes, and accumulating evidence has shown that NOX, particularly NOX1,2, and 4 which are highly expressed in the kidney,[87] play vital roles in intrarenal oxidative stress. Upregulated by metabolic factors, NOX leads to glomerular overproduction of ROS in podocytes, endothelial cells, and mesangial cells, which is closely associated with the initiation and progression of kidney diseases. Exposure of cultured mouse podocytes to high glucose resulted in apoptosis, which involved increased NOX activity and ROS production.[88] The transgenic TG(mRen2)27 rats, which harbor the mouse renin transgene and reninangiotensin system activation, shows increases in systolic blood pressure, albuminuria, renal NOX activity, accompanied by periarteriolar fibrosis and podocyte foot-process effacement. [89] NOX4 has also been identified as a critical mediator of high glucose- or angiotensin IIinduced mesangial cell activation. $[90,91]$

Even short exposure of vascular smooth muscle cells to AngII, which is often augmented in MetS, increases mRNA expression of NOX1 and NOX4 several-fold,[92] suggesting NOX activity is Ang II-dependent,[89]. Furthermore, additional mechanisms in injured kidneys may exacerbate oxidative stress, resulting in a vicious circle. TGF- $\beta$ increased in the rat kidney fibroblasts the activity of both NOX2 and NOX4.[93] Hence, there is close link between oxidative stress and kidney health. Therapeutic strategies targeting oxidative stress may be useful to prevent or alleviate kidney injury in MetS.

The mitochondrion is an intracellular organelle crucial for handling ROS production, which when excessive impairs cellular function. Under normal condition, mitochondria extract energy stored in nutrients that drives work within the body,[94-96] and a series of feedback and regulatory steps enables matching the rate of mitochondrial oxidative phosphorylation with cellular ATP demands.[97, 98] As the kidney has high energy demand and is rich in mitochondria, mitochondrial dysfunction plays a critical role in the pathogenesis of kidney diseases by affecting almost all renal cell types, $[99,100]$ including participating epithelialmesenchymal transition which contributes to loss of functional parenchyma.[101, 102]

In the setting of MetS, excessive nutrient availability supplies superfluous electrons to the respiratory chain, while lack of physical activity results in low ATP demand, favoring 
mitochondrial dysfunction and disproportionate superoxide formation.[103] Several elements that prevail in MetS may further disrupt mitochondrial function. Oxidized-LDL increases mitochondrial membrane potential and impairs redox status, [104] leading to apoptotic events; it may also cause vascular endothelial dysfunction by translocating mitochondrial proteins.[105] Patients with diabetic nephropathy demonstrate lower gene expression of the renal mitochondrial inner membrane organic anion transporters 1 and 3 , and of genes and proteins critical for mitochondrial biogenesis.[106] Similarly, their urine exosomes has decreased mitochondrial DNA.[106] NOX4-derived ROS decrease mitochondrial function in endothelial cells via disruption of the electron transport chain I, [107] and causes extracellular matrix protein accumulation in mesangial cells.[108, 109] Interestingly, these changes are associated with AMPK inactivation,[108] and its activation reduced renal fibrogenesis.[109] A key pathway by which AMPK stimulation protects cells in a calorie-deprived state is by stimulating the master regulator of mitochondrial biogenesis, PPAR- $\gamma$ coactivator-1a.[110] AMPK also inhibits activity of mammalian target of rapamycin, which mediates NOX4-induced podocyte injury,[111, 112] thereby preventing kidney damage progression.[113, 114] Furthermore, AngII not only increases mitochondrial production of ROS, [115] but may also promote mitochondrial degradation through the AT1receptor, and suppress their biogenesis through the AT2-receptor.[116, 117] Therefore, MetS may affect renal mitochondrial structure and function through several different pathways.

Mitochondrial dysfunction might also cause or worsen IR.[118] A 35\% decrease of mitochondrial DNA (mtDNA) density in peripheral blood cells precedes development of type-2 diabetes in patients.[119] Genetic studies also identified human mtDNA haplogroups that can modulate susceptibility to type-2 diabetes.[120] Interestingly, Rosiglitazone, one of the TZDs that increase insulin sensitivity, also recovers mitochondrial electron transport function in mice with aldosterone-induced mitochondrial dysfunction.[121] We have recently also found cardioprotective effects of mitochondrial-targeted peptides in MetS,[122] yet their effects on the kidney remain to be explored.

Taken together, mitochondrial function is vital in sensing and modulating energy metabolism in MetS, and development of mitochondria-targeting therapeutics may potentially benefit patients with MetS and associated tissue injury.

\section{Hypertension}

Hypertension is an important hallmark of MetS and a common cause of kidney disease. Several mechanisms link hypertension to MetS, among which obesity is a major contributor. Obesity alone is associated with an increase in the severity of hypertension and the number of required antihypertensive medications, and impedes achieving blood pressure control. [123] The direct link between hypertension and dyslipidemia-induced obesity was shown in animal studies. In rabbits, blood pressure rises by $6 \%$ after a one-week high-fat diet, and falls back after resumption of normal diet.[124] Adipocytes are rich sources of the precursor protein of AngII and angiotensinogen[125] as well as aldosterone synthase.[75] Indeed, plasma aldosterone is independently associated with obesity.[126] A 5\% weight loss in obese women reduces renin-angiotensin-aldosterone activity in both adipose tissue and plasma.[127] In addition, increased visceral and retroperitoneal fat may boost hypertension 
by compressing the kidneys. The intra-abdominal pressure in obese patients can be double that of normal subjects,[128, 129] and excessive fat accumulation in and around the kidneys is associated with increased intrarenal pressures, impaired pressure natriuresis, and hypertension.[130]

In addition to the effects of fat, high serum insulin level is associated with an increase in circulating levels of the potent vasoconstrictor endothelin-1 in healthy and IR individuals. [131] Endothelin-1 receptor antagonism effectively reduced blood pressure in animal models of IR and hypertension,[132] implicating endothelin-1 in their pathogenesis. Furthermore, when coexisting with hyperglycemia, insulin exhibits anti-natriuretic effect by promoting sodium retention.[133] As proximal tubular epithelial cells often undergo hypertrophy in obese subjects,[134] together they may account for increased sodium reabsorption and elevation of arterial pressure. As discussed earlier, increased leptin and reduced adiponectin in obesity may also increase sympathetic nerve activity, $[135,136]$ thus contribute to hypertension.

\section{Uric acid (UA)}

Hyperuricemia is commonly observed and strongly associated with MetS. The prevalence of MetS increased from $5.9 \%$ for uric acid levels under $6 \mathrm{mg} / \mathrm{dL}$ to $59.0 \%$ for levels $10 \mathrm{mg} / \mathrm{dL}$ or greater,[137] and hyperuricemia correlates with elevated fasting insulin level.[138] Moreover, based on a recent systemic review including 13 studies containing 190,718 participants, elevated serum uric acid levels showed an increased risk for development of chronic renal dysfunction.[139]

Animals studies have revealed that hyperuricemia caused IR possibly due to the proinflammatory effect of uric acid on adipocytes $[140,141]$ and impairment of insulindependent glucose uptake.[142] Using a uricase inhibitor, which leads to hyperuricemia, enabled observing a direct relationship between blood pressure and uric acid. In mice, blood pressure increases by $10-\mathrm{mm} \mathrm{Hg}$ for each $0.03-\mathrm{mmol} / \mathrm{L}(0.5-\mathrm{mg} / \mathrm{dL})$ incremental rise in serum uric acid.[143] Allopurinol, a uric acid lowering drug, prophylactically prevented hyperinsulinemia, systolic hypertension, and hypertriglyceridemia.[140] In rat kidneys, hyperuricemia increased juxtaglomerular renin and downregulated macula densa neuronal NO synthase.[143] In vitro, uric acid inhibited NO production in endothelial cells,[144] and dose-dependently inhibited endothelial vasodilatory response to acetylcholine,[140] which may in turn compromise blood and oxygen supply to the kidney. Evidently, decreasing uric acid levels may have beneficial effects in MetS.

\section{Conclusion}

Clearly, the impact of the MetS on the kidney is multifactorial. The current nutritional habits and lifestyles of many modern human subjects favors metabolic overload, which underpins chronic metabolic diseases. The kidney is a target organ susceptible to MetS (Figure 2), yet the appropriate treatment strategy for MetS-associated kidney disease remains to be identified. As MetS and type-2 diabetes share some common pathways (e.g. hyperfiltration, oxidative stress, etc.), MetS-associated kidney damage may resemble the early stage of 
diabetic nephropathy and merits further studies. In addition to screening, life-style modifications, and management of MetS risk factors and CKD, target-specific therapeutic interventions are in need and warrant investigation to prevent the development and slow the progression of CKD in MetS.

\section{Acknowledgments}

Partly supported by NIH Grants DK104273, DK102325, DK73608, DK100081, and HL123160.

\section{REFERENCES}

1. Grundy SM, Cleeman JI, Daniels SR, Donato KA, Eckel RH, Franklin BA, et al. Diagnosis and management of the metabolic syndrome: an American Heart Association/National Heart, Lung, and Blood Institute Scientific Statement. Circulation. 2005; 112:2735-2752. [PubMed: 16157765]

2. Alberti KG, Zimmet P, Shaw J. Metabolic syndrome--a new world-wide definition. A Consensus Statement from the International Diabetes Federation. Diabet Med. 2006; 23:469-480. [PubMed: 16681555]

3. Aguilar M, Bhuket T, Torres S, Liu B, Wong RJ. Prevalence of the metabolic syndrome in the United States, 2003-2012. JAMA. 2015; 313:1973-1974. [PubMed: 25988468]

4. Luk AO, So WY, Ma RC, Kong AP, Ozaki R, Ng VS, et al. Metabolic syndrome predicts new onset of chronic kidney disease in 5,829 patients with type 2 diabetes: a 5-year prospective analysis of the Hong Kong Diabetes Registry. Diabetes Care. 2008; 31:2357-2361. [PubMed: 18835954]

5. DeFina LF, Vega GL, Leonard D, Grundy SM. Fasting glucose, obesity, and metabolic syndrome as predictors of type 2 diabetes: the Cooper Center Longitudinal Study. J Investig Med. 2012; 60:1164-1168.

6. Hoehner CM, Greenlund KJ, Rith-Najarian S, Casper ML, McClellan WM. Association of the insulin resistance syndrome and microalbuminuria among nondiabetic native Americans The InterTribal Heart Project. J Am Soc Nephrol. 2002; 13:1626-1634. [PubMed: 12039992]

7. Locatelli F, Pozzoni P, Del Vecchio L. Renal manifestations in the metabolic syndrome. J Am Soc Nephrol. 2006; 17:S81-S85. [PubMed: 16565254]

8. Chen J, Muntner P, Hamm LL, Jones DW, Batuman V, Fonseca V, et al. The metabolic syndrome chronic kidney disease in U.S. adults. Ann Intern Med. 2004; 140:167-174. [PubMed: 14757614]

9. Alexander MP, Patel TV, Farag YM, Florez A, Rennke HG, Singh AK. Kidney pathological changes in metabolic syndrome: a cross-sectional study. Am J Kidney Dis. 2009; 53:751-759. [PubMed: 19339092]

10. Porrini E, Delgado P, Bigo C, Alvarez A, Cobo M, Checa MD, et al. Impact of metabolic syndrome on graft function and survival after cadaveric renal transplantation. Am J Kidney Dis. 2006; 48:134-142. [PubMed: 16797396]

11. de Vries AP, Bakker SJ, van Son WJ, van der Heide JJ, Ploeg RJ, The HT, et al. Metabolic syndrome is associated with impaired long-term renal allograft function; not all component criteria contribute equally. Am J Transplant. 2004; 4:1675-1683. [PubMed: 15367224]

12. Danziger J. The bone-renal axis in early chronic kidney disease: an emerging paradigm. Nephrol Dial Transplant. 2008; 23:2733-2737. [PubMed: 18469306]

13. Davies MR, Lund RJ, Mathew S, Hruska KA. Low turnover osteodystrophy and vascular calcification are amenable to skeletal anabolism in an animal model of chronic kidney disease and the metabolic syndrome. J Am Soc Nephrol. 2005; 16:917-928. [PubMed: 15743994]

14. Lerman LO, Lerman A. [The metabolic syndrome and early kidney disease: another link in the chain?]. Rev Esp Cardiol. 2011; 64:358-360. [PubMed: 21477912]

15. Zhang X, Li ZL, Woollard JR, Eirin A, Ebrahimi B, Crane JA, et al. Obesity-metabolic derangement preserves hemodynamics but promotes intrarenal adiposity and macrophage infiltration in swine renovascular disease. Am J Physiol Renal Physiol. 2013; 305:F265-F276. [PubMed: 23657852] 
16. Mostbeck GH, Kain R, Mallek R, Derfler K, Walter R, Havelec L, et al. Duplex Doppler sonography in renal parenchymal disease. Histopathologic correlation. J Ultrasound Med. 1991; 10:189-194. [PubMed: 2051529]

17. Buscemi S, Verga S, Batsis JA, Cottone S, Mattina A, Re A, et al. Intra-renal hemodynamics and carotid intima-media thickness in the metabolic syndrome. Diabetes Res Clin Pract. 2009; 86:177185. [PubMed: 19815301]

18. Sanchez-Lozada LG, Tapia E, Jimenez A, Bautista P, Cristobal M, Nepomuceno T, et al. Fructoseinduced metabolic syndrome is associated with glomerular hypertension and renal microvascular damage in rats. Am J Physiol Renal Physiol. 2007; 292:F423-F429. [PubMed: 16940562]

19. Nakagawa T, Kang DH, Ohashi R, Suga S, Herrera-Acosta J, Rodriguez-Iturbe B, et al. Tubulointerstitial disease: role of ischemia and microvascular disease. Curr Opin Nephrol Hypertens. 2003; 12:233-241. [PubMed: 12698060]

20. Costa C, Incio J, Soares R. Angiogenesis and chronic inflammation: cause or consequence? Angiogenesis. 2007; 10:149-166. [PubMed: 17457680]

21. Chade AR, Hall JE. Role of the Renal Microcirculation in Progression of Chronic Kidney Injury in Obesity. American journal of nephrology. 2016; 44:354-367. [PubMed: 27771702]

22. Li Z, Woollard JR, Wang S, Korsmo MJ, Ebrahimi B, Grande JP, et al. Increased glomerular filtration rate in early metabolic syndrome is associated with renal adiposity and microvascular proliferation. Am J Physiol Renal Physiol. 2011; 301:F1078-F1087. [PubMed: 21775485]

23. Li ZL, Woollard JR, Ebrahimi B, Crane JA, Jordan KL, Lerman A, et al. Transition from obesity to metabolic syndrome is associated with altered myocardial autophagy and apoptosis. Arterioscler Thromb Vasc Biol. 2012; 32:1132-1141. [PubMed: 22383702]

24. Kim YW, Byzova TV. Oxidative stress in angiogenesis and vascular disease. Blood. 2014; 123:625-631. [PubMed: 24300855]

25. Hale LJ, Hurcombe J, Lay A, Santamaria B, Valverde AM, Saleem MA, et al. Insulin directly stimulates VEGF-A production in the glomerular podocyte. Am J Physiol Renal Physiol. 2013; 305:F182-F188. [PubMed: 23698113]

26. Hall JE, do Carmo JM, da Silva AA, Wang Z, Hall ME. Obesity-induced hypertension: interaction of neurohumoral and renal mechanisms. Circulation research. 2015; 116:991-1006. [PubMed: 25767285]

27. Cohen AJ, McCarthy DM, Stoff JS. Direct hemodynamic effect of insulin in the isolated perfused kidney. Am J Physiol. 1989; 257:F580-F585. [PubMed: 2679144]

28. Hayashi K, Fujiwara K, Oka K, Nagahama T, Matsuda H, Saruta T. Effects of insulin on rat renal microvessels: studies in the isolated perfused hydronephrotic kidney. Kidney Int. 1997; 51:15071513. [PubMed: 9150466]

29. Ter Maaten JC, Bakker SJ, Serne EH, Moshage HJ, Donker AJ, Gans RO. Insulin-mediated increases in renal plasma flow are impaired in insulin-resistant normal subjects. Eur J Clin Invest. 2000; 30:1090-1098. [PubMed: 11122324]

30. Vicent D, Ilany J, Kondo T, Naruse K, Fisher SJ, Kisanuki YY, et al. The role of endothelial insulin signaling in the regulation of vascular tone and insulin resistance. J Clin Invest. 2003; 111:13731380. [PubMed: 12727929]

31. Burlacu A, Siriopol D, Voroneanu L, Nistor I, Hogas S, Nicolae A, et al. Atherosclerotic Renal Artery Stenosis Prevalence and Correlations in Acute Myocardial Infarction Patients Undergoing Primary Percutaneous Coronary Interventions: Data From Nonrandomized Single-Center Study (REN-ACS)-A Single Center, Prospective, Observational Study. J Am Heart Assoc. 2015; 4:e002379. [PubMed: 26459932]

32. Wellen KE, Hotamisligil GS. Inflammation, stress, and diabetes. J Clin Invest. 2005; 115:11111119. [PubMed: 15864338]

33. Sur G, Floca E, Kudor-Szabadi L, Sur ML, Sur D, Samasca G. The relevance of inflammatory markers in metabolic syndrome. Maedica (Buchar). 2014; 9:15-18. [PubMed: 25553120]

34. Hotamisligil GS. Inflammation and metabolic disorders. Nature. 2006; 444:860-867. [PubMed: 17167474] 
35. Dominguez J, Wu P, Packer CS, Temm C, Kelly KJ. Lipotoxic and inflammatory phenotypes in rats with uncontrolled metabolic syndrome and nephropathy. Am J Physiol Renal Physiol. 2007; 293:F670-F679. [PubMed: 17596532]

36. Al-Shanti N, Stewart CE. Inhibitory effects of IL-6 on IGF-1 activity in skeletal myoblasts could be mediated by the activation of SOCS-3. J Cell Biochem. 2012; 113:923-933. [PubMed: 22033984]

37. De Benedetti F, Meazza C, Oliveri M, Pignatti P, Vivarelli M, Alonzi T, et al. Effect of IL-6 on IGF binding protein-3: a study in IL-6 transgenic mice and in patients with systemic juvenile idiopathic arthritis. Endocrinology. 2001; 142:4818-4826. [PubMed: 11606449]

38. Bahceci M, Gokalp D, Bahceci S, Tuzcu A, Atmaca S, Arikan S. The correlation between adiposity and adiponectin, tumor necrosis factor alpha, interleukin- 6 and high sensitivity Creactive protein levels. Is adipocyte size associated with inflammation in adults? J Endocrinol Invest. 2007; 30:210-214. [PubMed: 17505154]

39. Ma S, Zhu XY, Eirin A, Woollard JR, Jordan KL, Tang H, et al. Perirenal fat promotes renal arterial endothelial dysfunction in obese swine through tumor necrosis factor-alpha. J Urol. 2015

40. Forsythe LK, Wallace JM, Livingstone MB. Obesity and inflammation: the effects of weight loss. Nutr Res Rev. 2008; 21:117-133. [PubMed: 19087366]

41. Abd, El-Kader MS., Al-Jiffri, O., Ashmawy, EM. Impact of weight loss on markers of systemic inflammation in obese Saudi children with asthma. Afr Health Sci. 2013; 13:682-688. [PubMed: 24250307]

42. Friedman JE, Dohm GL, Elton CW, Rovira A, Chen JJ, Leggett-Frazier N, et al. Muscle insulin resistance in uremic humans: glucose transport, glucose transporters, and insulin receptors. Am J Physiol. 1991; 261:E87-E94. [PubMed: 1858877]

43. Zhou R, Tardivel A, Thorens B, Choi I, Tschopp J. Thioredoxin-interacting protein links oxidative stress to inflammasome activation. Nat Immunol. 2010; 11:136-140. [PubMed: 20023662]

44. Goldfine AB, Fonseca V, Jablonski KA, Pyle L, Staten MA, Shoelson SE. The effects of salsalate on glycemic control in patients with type 2 diabetes: a randomized trial. Ann Intern Med. 2010; 152:346-357. [PubMed: 20231565]

45. Goldfine AB, Silver R, Aldhahi W, Cai D, Tatro E, Lee J, et al. Use of salsalate to target inflammation in the treatment of insulin resistance and type 2 diabetes. Clin Transl Sci. 2008; 1:36-43. [PubMed: 19337387]

46. Stanley TL, Zanni MV, Johnsen S, Rasheed S, Makimura H, Lee H, et al. TNF-alpha antagonism with etanercept decreases glucose and increases the proportion of high molecular weight adiponectin in obese subjects with features of the metabolic syndrome. J Clin Endocrinol Metab. 2011; 96:E146-E150. [PubMed: 21047923]

47. De Cosmo S, Menzaghi C, Prudente S, Trischitta V. Role of insulin resistance in kidney dysfunction: insights into the mechanism and epidemiological evidence. Nephrol Dial Transplant. 2013; 28:29-36. [PubMed: 23048172]

48. Kurella M, Lo JC, Chertow GM. Metabolic syndrome and the risk for chronic kidney disease among nondiabetic adults. J Am Soc Nephrol. 2005; 16:2134-2140. [PubMed: 15901764]

49. Chen J, Muntner P, Hamm LL, Fonseca V, Batuman V, Whelton PK, et al. Insulin resistance and risk of chronic kidney disease in nondiabetic US adults. J Am Soc Nephrol. 2003; 14:469-477. [PubMed: 12538749]

50. Groop PH, Forsblom C, Thomas MC. Mechanisms of disease: Pathway-selective insulin resistance and microvascular complications of diabetes. Nat Clin Pract Endocrinol Metab. 2005; 1:100-110. [PubMed: 16929378]

51. Nestler JE, Barlascini CO, Tetrault GA, Fratkin MJ, Clore JN, Blackard WG. Increased transcapillary escape rate of albumin in nondiabetic men in response to hyperinsulinemia. Diabetes. 1990; 39:1212-1217. [PubMed: 2210073]

52. Jheng HF, Tsai PJ, Chuang YL, Shen YT, Tai TA, Chen WC, et al. Albumin stimulates renal tubular inflammation through an HSP70-TLR4 axis in mice with early diabetic nephropathy. Dis Model Mech. 2015; 8:1311-1321. [PubMed: 26398934] 
53. Butlen D, Vadrot S, Roseau S, Morel F. Insulin receptors along the rat nephron: [125I] insulin binding in microdissected glomeruli and tubules. Pflugers Arch. 1988; 412:604-612. [PubMed: 3211711]

54. Nakamura R, Emmanouel DS, Katz AI. Insulin binding sites in various segments of the rabbit nephron. J Clin Invest. 1983; 72:388-392. [PubMed: 6348088]

55. Mima A, Ohshiro Y, Kitada M, Matsumoto M, Geraldes P, Li C, et al. Glomerular-specific protein kinase C-beta-induced insulin receptor substrate-1 dysfunction and insulin resistance in rat models of diabetes and obesity. Kidney Int. 2011; 79:883-896. [PubMed: 21228767]

56. Kim EY, Dryer SE. Effects of insulin and high glucose on mobilization of slo1 BKCa channels in podocytes. J Cell Physiol. 2011; 226:2307-2315. [PubMed: 21660954]

57. Kim EY, Anderson M, Dryer SE. Insulin increases surface expression of TRPC6 channels in podocytes: role of NADPH oxidases and reactive oxygen species. Am J Physiol Renal Physiol. 2012; 302:F298-F307. [PubMed: 22031853]

58. Wang S, Denichilo M, Brubaker C, Hirschberg R. Connective tissue growth factor in tubulointerstitial injury of diabetic nephropathy. Kidney Int. 2001; 60:96-105. [PubMed: $11422741]$

59. Namikoshi T, Tomita N, Satoh M, Haruna Y, Kobayashi S, Komai N, et al. Pioglitazone enhances the antihypertensive and renoprotective effects of candesartan in Zucker obese rats fed a highprotein diet. Hypertens Res. 2008; 31:745-755. [PubMed: 18633187]

60. Busch M, Franke S, Ruster C, Wolf G. Advanced glycation end-products and the kidney. Eur J Clin Invest. 2010; 40:742-755. [PubMed: 20649640]

61. Ruster C, Wolf G. Adipokines promote chronic kidney disease. Nephrol Dial Transplant. 2013; (28 Suppl 4):8-14.

62. Miyamoto S, Sharma K. Adipokines protecting CKD. Nephrol Dial Transplant. 2013; (28 Suppl 4): $15-22$.

63. Sharma K. The link between obesity and albuminuria: adiponectin and podocyte dysfunction. Kidney Int. 2009; 76:145-148. [PubMed: 19404275]

64. Sharma K, Ramachandrarao S, Qiu G, Usui HK, Zhu Y, Dunn SR, et al. Adiponectin regulates albuminuria and podocyte function in mice. J Clin Invest. 2008; 118:1645-1656. [PubMed: 18431508]

65. Rutkowski JM, Wang ZV, Park AS, Zhang J, Zhang D, Hu MC, et al. Adiponectin promotes functional recovery after podocyte ablation. J Am Soc Nephrol. 2013; 24:268-282. [PubMed: 23334396]

66. Lee MP, Orlov D, Sweeney G. Leptin induces rat glomerular mesangial cell hypertrophy, but does not regulate hyperplasia or apoptosis. Int J Obes (Lond). 2005; 29:1395-1401. [PubMed: 15997243]

67. Chen KH, Hung CC, Hsu HH, Jing YH, Yang CW, Chen JK. Resveratrol ameliorates early diabetic nephropathy associated with suppression of augmented TGF-beta/smad and ERK1/2 signaling in streptozotocin-induced diabetic rats. Chem Biol Interact. 2011; 190:45-53. [PubMed: 21300041]

68. Kumpers P, Gueler F, Rong S, Mengel M, Tossidou I, Peters I, et al. Leptin is a coactivator of TGFbeta in unilateral ureteral obstructive kidney disease. Am J Physiol Renal Physiol. 2007; 293:F1355-F1362. [PubMed: 17686962]

69. Kusminski CM, McTernan PG, Kumar S. Role of resistin in obesity, insulin resistance and Type II diabetes. Clin Sci (Lond). 2005; 109:243-256. [PubMed: 16104844]

70. Menzaghi C, Salvemini L, Fini G, Thompson R, Mangiacotti D, Di Paola R, et al. Serum resistin and kidney function: a family-based study in non-diabetic, untreated individuals. PLoS One. 2012; 7:e38414. [PubMed: 22701635]

71. Axelsson J, Bergsten A, Qureshi AR, Heimburger O, Barany P, Lonnqvist F, et al. Elevated resistin levels in chronic kidney disease are associated with decreased glomerular filtration rate and inflammation, but not with insulin resistance. Kidney Int. 2006; 69:596-604. [PubMed: 16395259]

72. Habeeballah H, Alsuhaymi N, Stebbing MJ, Jenkins TA, Badoer E. Central leptin and resistin combined elicit enhanced central effects on renal sympathetic nerve activity. Exp Physiol. 2016; 101:791-800. [PubMed: 27151838] 
73. Kosari S, Rathner JA, Badoer E. Central resistin enhances renal sympathetic nerve activity via phosphatidylinositol 3-kinase but reduces the activity to brown adipose tissue via extracellular signal-regulated kinase 1/2. J Neuroendocrinol. 2012; 24:1432-1439. [PubMed: 22702339]

74. Hall JE, Brands MW, Dixon WN, Smith MJ Jr. Obesity-induced hypertension. Renal function and systemic hemodynamics. Hypertension (Dallas, Tex : 1979). 1993; 22:292-299.

75. Briones AM, Nguyen Dinh Cat A, Callera GE, Yogi A, Burger D, He Y, et al. Adipocytes produce aldosterone through calcineurin-dependent signaling pathways: implications in diabetes mellitusassociated obesity and vascular dysfunction. Hypertension (Dallas, Tex : 1979). 2012; 59:10691078.

76. Fujita T. Aldosterone in salt-sensitive hypertension and metabolic syndrome. J Mol Med (Berl). 2008; 86:729-734. [PubMed: 18437332]

77. Kriz W, Elger M, Mundel P, Lemley KV. Structure-stabilizing forces in the glomerular tuft. J Am Soc Nephrol. 1995; 5:1731-1739. [PubMed: 7787139]

78. Chen HM, Liu ZH, Zeng CH, Li SJ, Wang QW, Li LS. Podocyte lesions in patients with obesityrelated glomerulopathy. Am J Kidney Dis. 2006; 48:772-779. [PubMed: 17059996]

79. Wiggins JE, Goyal M, Sanden SK, Wharram BL, Shedden KA, Misek DE, et al. Podocyte hypertrophy, "adaptation," and "decompensation" associated with glomerular enlargement and glomerulosclerosis in the aging rat: prevention by calorie restriction. J Am Soc Nephrol. 2005; 16:2953-2966. [PubMed: 16120818]

80. Kriz W, Hosser H, Hahnel B, Gretz N, Provoost AP. From segmental glomerulosclerosis to total nephron degeneration and interstitial fibrosis: a histopathological study in rat models and human glomerulopathies. Nephrol Dial Transplant. 1998; 13:2781-2798. [PubMed: 9829480]

81. Fukuda A, Chowdhury MA, Venkatareddy MP, Wang SQ, Nishizono R, Suzuki T, et al. Growthdependent podocyte failure causes glomerulosclerosis. J Am Soc Nephrol. 2012; 23:1351-1363. [PubMed: 22773827]

82. Kambham N, Markowitz GS, Valeri AM, Lin J, D’Agati VD. Obesity-related glomerulopathy: an emerging epidemic. Kidney Int. 2001; 59:1498-1509. [PubMed: 11260414]

83. D'Agati VD, Chagnac A, de Vries AP, Levi M, Porrini E, Herman-Edelstein M, et al. Obesityrelated glomerulopathy: clinical and pathologic characteristics and pathogenesis. Nat Rev Nephrol. 2016; 12:453-471. [PubMed: 27263398]

84. Fortuno A, San Jose G, Moreno MU, Beloqui O, Diez J, Zalba G. Phagocytic NADPH oxidase overactivity underlies oxidative stress in metabolic syndrome. Diabetes. 2006; 55:209-215. [PubMed: 16380495]

85. Huang PL. Unraveling the links between diabetes, obesity, and cardiovascular disease. Circulation research. 2005; 96:1129-1131. [PubMed: 15947251]

86. Furukawa S, Fujita T, Shimabukuro M, Iwaki M, Yamada Y, Nakajima Y, et al. Increased oxidative stress in obesity and its impact on metabolic syndrome. J Clin Invest. 2004; 114:1752-1761. [PubMed: 15599400]

87. Geiszt M, Kopp JB, Varnai P, Leto TL. Identification of renox, an NAD(P)H oxidase in kidney. Proc Natl Acad Sci U S A. 2000; 97:8010-8014. [PubMed: 10869423]

88. Eid AA, Gorin Y, Fagg BM, Maalouf R, Barnes JL, Block K, et al. Mechanisms of podocyte injury in diabetes: role of cytochrome P450 and NADPH oxidases. Diabetes. 2009; 58:1201-1211. [PubMed: 19208908]

89. Whaley-Connell A, Habibi J, Nistala R, Cooper SA, Karuparthi PR, Hayden MR, et al. Attenuation of NADPH oxidase activation and glomerular filtration barrier remodeling with statin treatment. Hypertension (Dallas, Tex : 1979). 2008; 51:474-480.

90. Block K, Eid A, Griendling KK, Lee DY, Wittrant Y, Gorin Y. Nox4 NAD(P)H oxidase mediates Src-dependent tyrosine phosphorylation of PDK-1 in response to angiotensin II: role in mesangial cell hypertrophy and fibronectin expression. J Biol Chem. 2008; 283:24061-24076. [PubMed: 18559349]

91. Block K, Gorin Y, Abboud HE. Subcellular localization of Nox4 and regulation in diabetes. Proc Natl Acad Sci U S A. 2009; 106:14385-14390. [PubMed: 19706525] 
92. Wingler K, Wunsch S, Kreutz R, Rothermund L, Paul M, Schmidt HH. Upregulation of the vascular NAD(P)H-oxidase isoforms Nox 1 and Nox4 by the renin-angiotensin system in vitro and in vivo. Free Radic Biol Med. 2001; 31:1456-1464. [PubMed: 11728818]

93. Bondi CD, Manickam N, Lee DY, Block K, Gorin Y, Abboud HE, et al. NAD(P)H oxidase mediates TGF-beta1-induced activation of kidney myofibroblasts. J Am Soc Nephrol. 2010; 21:93-102. [PubMed: 19926889]

94. Nunnari J, Suomalainen A. Mitochondria: in sickness and in health. Cell. 2012; 148:1145-1159. [PubMed: 22424226]

95. Wallace DC, Fan W, Procaccio V. Mitochondrial energetics and therapeutics. Annu Rev Pathol. 2010; 5:297-348. [PubMed: 20078222]

96. Duchen MR, Szabadkai G. Roles of mitochondria in human disease. Essays Biochem. 2010; 47:115-137. [PubMed: 20533904]

97. Brand MD, Murphy MP. Control of electron flux through the respiratory chain in mitochondria and cells. Biol Rev Camb Philos Soc. 1987; 62:141-193. [PubMed: 3300795]

98. Brown GC. Control of respiration and ATP synthesis in mammalian mitochondria and cells. Biochem J. 1992; 284(Pt 1):1-13. [PubMed: 1599389]

99. Eirin A, Lerman A, Lerman LO. The Emerging Role of Mitochondrial Targeting in Kidney Disease. Handb Exp Pharmacol. 2016

100. Eirin A, Lerman A, Lerman LO. Mitochondria: a pathogenic paradigm in hypertensive renal disease. Hypertension (Dallas, Tex : 1979). 2015; 65:264-270.

101. Granata S, Dalla Gassa A, Tomei P, Lupo A, Zaza G. Mitochondria: a new therapeutic target in chronic kidney disease. Nutr Metab (Lond). 2015; 12:49. [PubMed: 26612997]

102. Lovisa S, Zeisberg M, Kalluri R. Partial Epithelial-to-Mesenchymal Transition and Other New Mechanisms of Kidney Fibrosis. Trends Endocrinol Metab. 2016; 27:681-695. [PubMed: 27372267]

103. Bonnard C, Durand A, Peyrol S, Chanseaume E, Chauvin MA, Morio B, et al. Mitochondrial dysfunction results from oxidative stress in the skeletal muscle of diet-induced insulin-resistant mice. J Clin Invest. 2008; 118:789-800. [PubMed: 18188455]

104. Takabe W, Li R, Ai L, Yu F, Berliner JA, Hsiai TK. Oxidized low-density lipoprotein-activated cJun NH2-terminal kinase regulates manganese superoxide dismutase ubiquitination: implication for mitochondrial redox status and apoptosis. Arterioscler Thromb Vasc Biol. 2010; 30:436-441. [PubMed: 20139358]

105. Pandey D, Bhunia A, Oh YJ, Chang F, Bergman Y, Kim JH, et al. OxLDL triggers retrograde translocation of arginase 2 in aortic endothelial cells via ROCK and mitochondrial processing peptidase. Circulation research. 2014; 115:450-459. [PubMed: 24903103]

106. Sharma K, Karl B, Mathew AV, Gangoiti JA, Wassel CL, Saito R, et al. Metabolomics reveals signature of mitochondrial dysfunction in diabetic kidney disease. J Am Soc Nephrol. 2013; 24:1901-1912. [PubMed: 23949796]

107. Koziel R, Pircher H, Kratochwil M, Lener B, Hermann M, Dencher NA, et al. Mitochondrial respiratory chain complex I is inactivated by NADPH oxidase Nox4. Biochem J. 2013; 452:231239. [PubMed: 23514110]

108. Papadimitriou A, Peixoto EB, Silva KC, Lopes de Faria JM, Lopes de Faria JB. Inactivation of AMPK mediates high phosphate-induced extracellular matrix accumulation via NOX4/TGFss-1 signaling in human mesangial cells. Cell Physiol Biochem. 2014; 34:1260-1272. [PubMed: 25278128]

109. Eid AA, Lee DY, Roman LJ, Khazim K, Gorin Y. Sestrin 2 and AMPK connect hyperglycemia to Nox4-dependent endothelial nitric oxide synthase uncoupling and matrix protein expression. Mol Cell Biol. 2013; 33:3439-3460. [PubMed: 23816887]

110. Dugan LL, You YH, Ali SS, Diamond-Stanic M, Miyamoto S, DeCleves AE, et al. AMPK dysregulation promotes diabetes-related reduction of superoxide and mitochondrial function. $\mathrm{J}$ Clin Invest. 2013; 123:4888-4899. [PubMed: 24135141]

111. Eid AA, Ford BM, Bhandary B, de Cassia Cavaglieri R, Block K, Barnes JL, et al. Mammalian target of rapamycin regulates Nox4-mediated podocyte depletion in diabetic renal injury. Diabetes. 2013; 62:2935-2947. [PubMed: 23557706] 
112. Eid AA, Ford BM, Block K, Kasinath BS, Gorin Y, Ghosh-Choudhury G, et al. AMP-activated protein kinase (AMPK) negatively regulates Nox4-dependent activation of p53 and epithelial cell apoptosis in diabetes. J Biol Chem. 2010; 285:37503-37512. [PubMed: 20861022]

113. Godel M, Hartleben B, Herbach N, Liu S, Zschiedrich S, Lu S, et al. Role of mTOR in podocyte function and diabetic nephropathy in humans and mice. J Clin Invest. 2011; 121:2197-2209. [PubMed: 21606591]

114. Sharma K. Obesity, oxidative stress, and fibrosis in chronic kidney disease. Kidney international supplements. 2014; 4:113-117. [PubMed: 25401040]

115. Dikalov SI, Nazarewicz RR. Angiotensin II-induced production of mitochondrial reactive oxygen species: potential mechanisms and relevance for cardiovascular disease. Antioxid Redox Signal. 2013; 19:1085-1094. [PubMed: 22443458]

116. Mitsuishi M, Miyashita K, Muraki A, Itoh H. Angiotensin II reduces mitochondrial content in skeletal muscle and affects glycemic control. Diabetes. 2009; 58:710-717. [PubMed: 19074984]

117. Abadir PM, Foster DB, Crow M, Cooke CA, Rucker JJ, Jain A, et al. Identification and characterization of a functional mitochondrial angiotensin system. Proc Natl Acad Sci U S A. 2011; 108:14849-14854. [PubMed: 21852574]

118. Hoehn KL, Salmon AB, Hohnen-Behrens C, Turner N, Hoy AJ, Maghzal GJ, et al. Insulin resistance is a cellular antioxidant defense mechanism. Proc Natl Acad Sci U S A. 2009; 106:17787-17792. [PubMed: 19805130]

119. Lee HK, Song JH, Shin CS, Park DJ, Park KS, Lee KU, et al. Decreased mitochondrial DNA content in peripheral blood precedes the development of non-insulin-dependent diabetes mellitus. Diabetes Res Clin Pract. 1998; 42:161-167. [PubMed: 9925346]

120. Fuku N, Park KS, Yamada Y, Nishigaki Y, Cho YM, Matsuo H, et al. Mitochondrial haplogroup N9a confers resistance against type 2 diabetes in Asians. Am J Hum Genet. 2007; 80:407-415. [PubMed: 17273962]

121. Zhu C, Huang S, Yuan Y, Ding G, Chen R, Liu B, et al. Mitochondrial dysfunction mediates aldosterone-induced podocyte damage: a therapeutic target of PPARgamma. Am J Pathol. 2011; 178:2020-2031. [PubMed: 21514419]

122. Eirin A, Ebrahimi B, Kwon SH, Fiala JA, Williams BJ, Woollard JR, et al. Restoration of Mitochondrial Cardiolipin Attenuates Cardiac Damage in Swine Renovascular Hypertension. J Am Heart Assoc. 2016:5.

123. Cushman WC, Ford CE, Cutler JA, Margolis KL, Davis BR, Grimm RH, et al. Success and predictors of blood pressure control in diverse North American settings: the antihypertensive and lipid-lowering treatment to prevent heart attack trial (ALLHAT). J Clin Hypertens (Greenwich). 2002; 4:393-404. [PubMed: 12461301]

124. Armitage JA, Burke SL, Prior LJ, Barzel B, Eikelis N, Lim K, et al. Rapid onset of renal sympathetic nerve activation in rabbits fed a high-fat diet. Hypertension (Dallas, Tex : 1979). 2012; 60:163-171.

125. Yvan-Charvet L, Quignard-Boulange A. Role of adipose tissue renin-angiotensin system in metabolic and inflammatory diseases associated with obesity. Kidney Int. 2011; 79:162-168. [PubMed: 20944545]

126. Buglioni A, Cannone V, Cataliotti A, Sangaralingham SJ, Heublein DM, Scott CG, et al. Circulating aldosterone and natriuretic peptides in the general community: relationship to cardiorenal and metabolic disease. Hypertension (Dallas, Tex : 1979). 2015; 65:45-53.

127. Engeli S, Bohnke J, Gorzelniak K, Janke J, Schling P, Bader M, et al. Weight loss and the reninangiotensin-aldosterone system. Hypertension (Dallas, Tex : 1979). 2005; 45:356-362.

128. Sugerman H, Windsor A, Bessos M, Wolfe L. Intra-abdominal pressure, sagittal abdominal diameter and obesity comorbidity. J Intern Med. 1997; 241:71-79. [PubMed: 9042096]

129. Cobb WS, Burns JM, Kercher KW, Matthews BD, James Norton H, Todd Heniford B. Normal intraabdominal pressure in healthy adults. J Surg Res. 2005; 129:231-235. [PubMed: 16140336]

130. Hall ME, do Carmo JM, da Silva AA, Juncos LA, Wang Z, Hall JE. Obesity, hypertension, and chronic kidney disease. Int J Nephrol Renovasc Dis. 2014; 7:75-88. [PubMed: 24600241]

131. Sarafidis PA, Bakris GL. Review: Insulin and endothelin: an interplay contributing to hypertension development? J Clin Endocrinol Metab. 2007; 92:379-385. [PubMed: 17118997] 
132. Miller AW, Tulbert C, Puskar M, Busija DW. Enhanced endothelin activity prevents vasodilation to insulin in insulin resistance. Hypertension (Dallas, Tex : 1979). 2002; 40:78-82.

133. Brands MW, Manhiani MM. Sodium-retaining effect of insulin in diabetes. Am J Physiol Regul Integr Comp Physiol. 2012; 303:R1101-R1109. [PubMed: 23034715]

134. Tobar A, Ori Y, Benchetrit S, Milo G, Herman-Edelstein M, Zingerman B, et al. Proximal tubular hypertrophy and enlarged glomerular and proximal tubular urinary space in obese subjects with proteinuria. PLoS One. 2013; 8:e75547. [PubMed: 24086563]

135. Ohashi K, Kihara S, Ouchi N, Kumada M, Fujita K, Hiuge A, et al. Adiponectin replenishment ameliorates obesity-related hypertension. Hypertension (Dallas, Tex : 1979). 2006; 47:11081116.

136. Carlyle M, Jones OB, Kuo JJ, Hall JE. Chronic cardiovascular and renal actions of leptin: role of adrenergic activity. Hypertension (Dallas, Tex : 1979). 2002; 39:496-501.

137. Choi HK, Ford ES. Prevalence of the metabolic syndrome in individuals with hyperuricemia. Am J Med. 2007; 120:442-447. [PubMed: 17466656]

138. Yoo TW, Sung KC, Shin HS, Kim BJ, Kim BS, Kang JH, et al. Relationship between serum uric acid concentration and insulin resistance and metabolic syndrome. Circ J. 2005; 69:928-933. [PubMed: 16041161]

139. Li L, Yang C, Zhao Y, Zeng X, Liu F, Fu P. Is hyperuricemia an independent risk factor for newonset chronic kidney disease?: A systematic review and meta-analysis based on observational cohort studies. BMC Nephrol. 2014; 15:122. [PubMed: 25064611]

140. Nakagawa T, Hu H, Zharikov S, Tuttle KR, Short RA, Glushakova O, et al. A causal role for uric acid in fructose-induced metabolic syndrome. Am J Physiol Renal Physiol. 2006; 290:F625F631. [PubMed: 16234313]

141. Baldwin W, McRae S, Marek G, Wymer D, Pannu V, Baylis C, et al. Hyperuricemia as a mediator of the proinflammatory endocrine imbalance in the adipose tissue in a murine model of the metabolic syndrome. Diabetes. 2011; 60:1258-1269. [PubMed: 21346177]

142. Zhi L, Yuzhang Z, Tianliang H, Hisatome I, Yamamoto T, Jidong C. High Uric Acid Induces Insulin Resistance in Cardiomyocytes In Vitro and In Vivo. PLoS One. 2016; 11:e0147737. [PubMed: 26836389]

143. Mazzali M, Hughes J, Kim YG, Jefferson JA, Kang DH, Gordon KL, et al. Elevated uric acid increases blood pressure in the rat by a novel crystal-independent mechanism. Hypertension. 2001; 38:1101-1106. [PubMed: 11711505]

144. Khosla UM, Zharikov S, Finch JL, Nakagawa T, Roncal C, Mu W, et al. Hyperuricemia induces endothelial dysfunction. Kidney Int. 2005; 67:1739-1742. [PubMed: 15840020] 

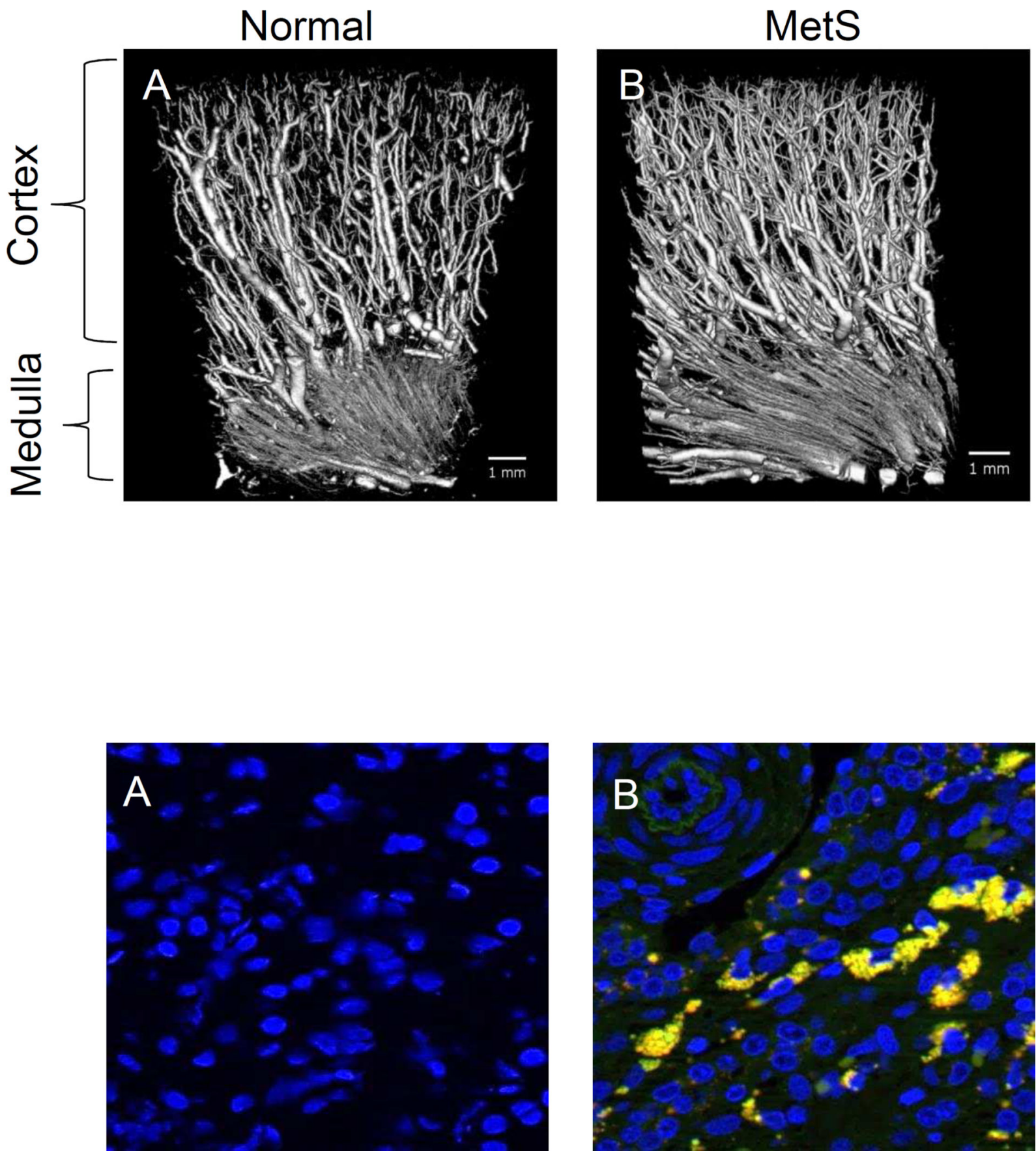

Figure 1.

(Top) Microvascular proliferation in MetS kidneys. Three-dimensional micro-CT reveals increased microvascular density in swine MetS (B) compared to normal (A) kidney.

Reproduced with permission.19 (Bottom) Proinflammatory macrophages infiltration in MetS kidney. Amplified infiltration of proinflammatory CD68+ (green) and inducible nitric oxide synthase+ (red) double-positive (yellow, white arrow) macrophages in a stenotic kidney with concurrent MetS (B) compared to control kidney (A). 


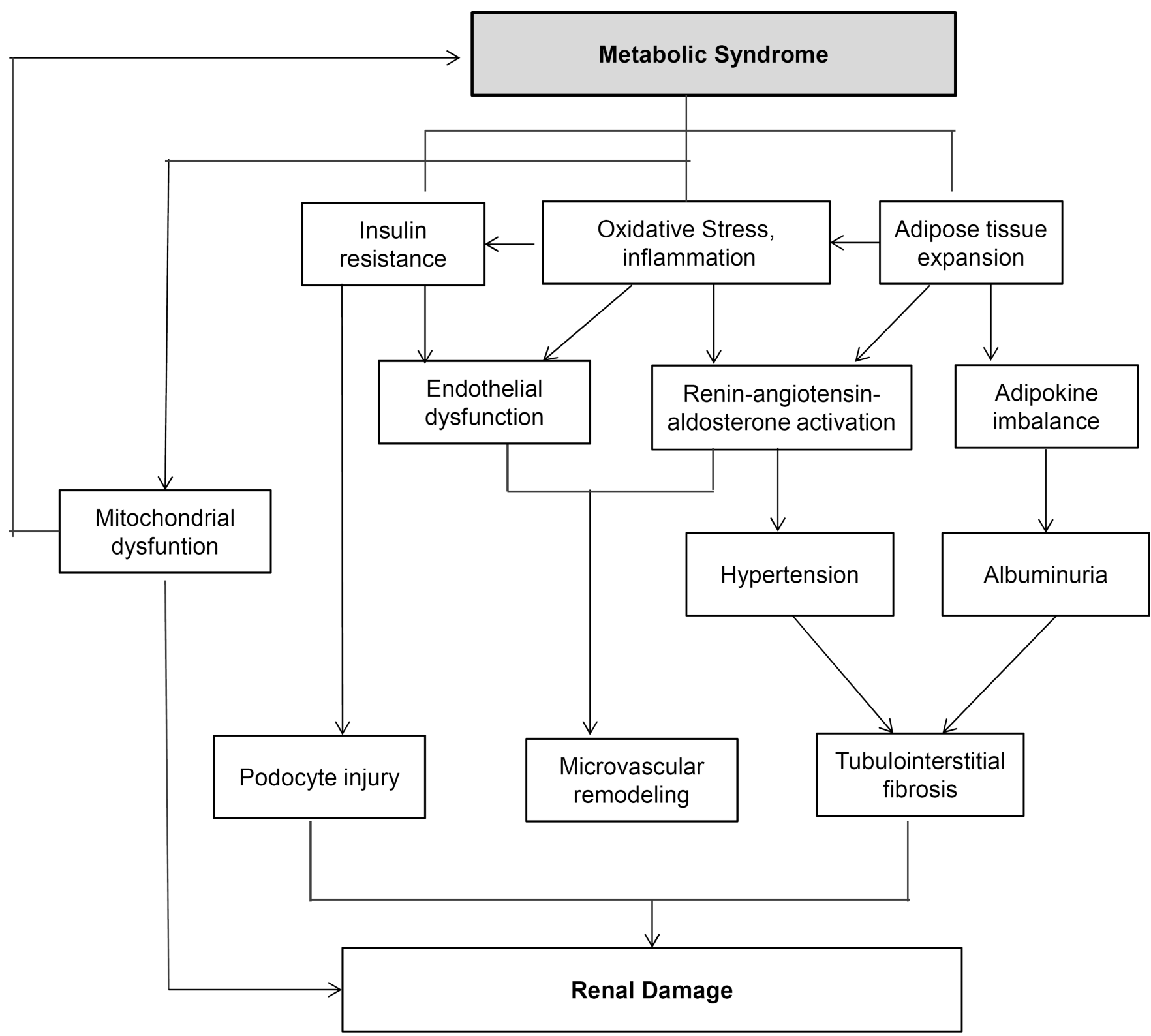

Figure 2.

Potential mechanisms by which MetS promotes kidney injury. Fundamental manifestations of MetS include insulin resistance and adipose tissue expansion, the latter promoting chronic inflammation and oxidative stress, which exacerbate insulin resistance. Those in turn can elicit various kidney injurious events through endothelial dysfunction, renin-angiotensinaldosterone activation, and hypertension, as well as via adipokine imbalance. MetS is also closely linked to mitochondrial dysfunction, which can both promote progression of kidney damage and development of MetS. 